\title{
Goodpasture's Syndrome with Negative Anti-glomerular Basement Membrane Antibodies
}

\author{
Tjitske Berends-De Vries ${ }^{1}$, Susan Boerma², Joan Doornebal ${ }^{2}$, Bert Dikkeschei ${ }^{3}$, Coen Stegeman ${ }^{4}$, Thiemo F. Veneman ${ }^{1}$ \\ ${ }^{1}$ Department of Intensive Care Medicine, Ziekenhuisgroep Twente, Almelo, The Netherlands \\ ${ }^{2}$ Department of Internal Medicine, Isala Klinieken, Zwolle, The Netherlands \\ ${ }^{3}$ Department of Clinical Chemistry, Isala Klinieken, Zwolle, The Netherlands \\ ${ }^{4}$ Department of Nephrology, University Hospital Groningen, Groningen, The Netherlands
}

\section{Doi: 10.12890/2017_000687 - European Journal of Case Reports in Internal Medicine - @ EFIM 2017}

\begin{abstract}
Received: 25/06/2017
Accepted: $28 / 06 / 2017$
\end{abstract}

Published: $13 / 07 / 2017$ How to cite this article: Berends-De Vries T, Boerma S, Doornebal J, Dikkeschei B, Stegeman C, Veneman TF. Goodpasture's syndrome with negative anti-
glomerular basement membrane antibodies . EJCRIM 2017;4: doi:10.12890/2017_000687.

Conflicts of Interests: The Authors declare that there are no competing interests.

This article is licensed under a Commons Attribution Non-Commercial 4.0 License

\section{ABSTRACT}

A young male patient with rapidly progressive and life-threatening pulmonary haemorrhage due to anti-glomerular basement membrane (anti-GBM) antibody disease without renal involvement repeatedly tested negative for serum anti-GBM antibodies. Although rare, antiGBM antibody disease should be considered in the differential diagnosis in patients with life-threatening pulmonary haemorrhage due to isolated diffuse alveolar haemorrhage. Enzyme-linked-immunosorbent assay (ELISA) testing for anti-GBM antibodies in anti-GBM antibody disease can give false-negative results. A negative serum anti-GBM antibody test is therefore insufficient to exclude the diagnosis. Thus, a kidney or lung biopsy should be considered in any case with a high clinical suspicion but negative anti-GBM antibody test to confirm or rule out the diagnosis.

\section{LEARNING POINTS}

- Diffuse alveolar haemorrhage (DAH) is a life-threatening disorder caused by severe damage due to injury or inflammation of the alveolarcapillary basement membrane.

- Anti-GBM antibody disease is a rare autoimmune disorder with circulating autoantibodies directed against the alpha-3 chain[Q2] of type VI collagen of the glomerular and/or alveolar basement membrane which may result in oliguric acute kidney failure due to rapidly progressive glomerulonephritis with or without DAH (commonly referred to as Goodpasture's syndrome).

- A kidney or lung biopsy should be considered to confirm or rule out the diagnosis if there is a high clinical suspicion but the anti-GBM antibody test is negative; prompt diagnosis and initiation of plasmapheresis, cyclophosphamide and prednisone therapy is essential.

\section{KEYWORDS}

Goodpasture, diffuse alveolar hemorrhage, anti-GBM antibodies 


\section{INTRODUCTION}

Diffuse alveolar haemorrhage (DAH) is a life-threatening disorder caused by severe damage due to injury or inflammation of the alveolarcapillary basement membrane. DAH is a life-threatening condition with a high mortality rate of up to $50 \%{ }^{[1]}$. The differential diagnosis of DAH is extensive and includes physical, toxic, infectious, immunological and neoplastic causes. DAH as a result of a systemic illness can be due to the small vessel vasculitides granulomatosis with polyangiitis (GPA) and microscopic polyangiitis (MPA), systemic lupus erythematosus (SLE) or anti-glomerular basement membrane (GBM) antibody disease.

Anti-GBM antibody disease is a rare autoimmune disorder with circulating autoantibodies directed against the alpha-3 chain of type $\mathrm{VI}$ collagen of the glomerular and/or alveolar basement membrane which may result in oliguric acute kidney failure due to rapidly progressive glomerulonephritis with or without DAH (commonly referred to as Goodpasture's syndrome) ${ }^{[1,2]}$. The detection of anti-GBM antibodies is essential for establishing the diagnosis of anti-GBM antibody disease. Antibodies can be detected either in the circulation or in a biopsy of kidney or lung tissue ${ }^{[1]}$. Patient survival was very poor but has dramatically improved since the introduction of combined immunosuppressive treatment consisting of plasmapheresis, cyclophosphamide and prednisone ${ }^{[3]}$. Thus, prompt diagnosis and initiation of therapy is essential. We describe a young male patient with rapidly progressive and life-threatening pulmonary haemorrhage due to anti-GBM antibody disease without renal involvement, who repeatedly tested negative for serum anti-GBM antibodies.

\section{CASE}

Our patient, a 32-year-old man, had been well until 3 weeks before admission when fever and a productive cough with brownish sputum developed. On admission, he presented with rapidly progressive shortness of breath. His medical history was unremarkable. The patient did not use any medications and had no known drug allergies. He smoked 15-20 cigarettes a day and denied use of illicit drugs. On physical examination he was in severe respiratory distress. His blood pressure was $147 / 85 \mathrm{mmHg}$, pulse was 110 beats per minute, respiratory rate was 24 breaths per minute, peripheral oxygen saturation was $89 \%$ in ambient air and temperature was $38.5^{\circ} \mathrm{C}$. On auscultation of the lungs, bilateral vesicular breath sounds and rhonchi were heard. The remainder of the physical examination was unremarkable. The results of laboratory investigations are shown in Table 1.

\begin{tabular}{|l|l|l|l|l|l|}
\hline Haemoglobin & $8.7 \mathrm{mmol} / \mathrm{I}$ & Ca & $2.01 \mathrm{mmol} / \mathrm{I}$ & $\mathrm{pO} 2$ & $18.8 \mathrm{kPa}$ \\
\hline Leukocytes & $19.4 \times 10^{9} / \mathrm{l}$ & Fosf & $0.77 \mathrm{mmol} / \mathrm{l}$ & Bic & $23 \mathrm{mmol} / \mathrm{l}$ \\
\hline Thrombocytes & $332 \times 10^{9} / \mathrm{l}$ & Albumin & $30 \mathrm{~g} / \mathrm{l}$ & ANA & Negative \\
\hline APTT & $36 \mathrm{sec}$ & ASAT & $18 \mathrm{U} / \mathrm{l}$ & ANCA & Negative \\
\hline PT & 1.2 & ALAT & $41 \mathrm{U} / \mathrm{l}$ & Anti-GBM & Negative \\
\hline C-reactive protein & $70 \mathrm{mg} / \mathrm{l}$ & AF & $89 \mathrm{U} / \mathrm{l}$ & Cocaine screening & Negative \\
\hline Creatinine & $97 \mu \mathrm{mol} / \mathrm{I}$ & GGT & $54 \mathrm{U} / \mathrm{l}$ & & \\
\hline eGFR & $78 \mathrm{ml} / \mathrm{min}$ & LDH & $232 \mathrm{U} / \mathrm{l}$ & & \\
\hline Na & $139 \mathrm{mmol} / \mathrm{l}$ & pH & 7.36 & & \\
\hline K & $3.8 \mathrm{mmol} / \mathrm{l}$ & pCO2 & $5.6 \mathrm{kPa}$ & & \\
\hline
\end{tabular}

Table 1. Laboratory investigations

The laboratory findings were notable for an inflammatory response (leucocytosis $19.4 \times 10^{9} / \mathrm{I}$ and C-reactive protein $70 \mathrm{mg} / \mathrm{l}$ ) and slightly impaired renal function (serum creatinine $97 \mu \mathrm{mol} / \mathrm{l}$, estimated glomerular filtration rate $78 \mathrm{ml} / \mathrm{min} / 1.73 \mathrm{~m} 2$ ). Urine analysis showed a (non) glomerular erythrocyturia and mild proteinuria (0.2-0.5 g/l) (Table 2). An electrocardiogram showed sinus tachycardia. A chest x-ray showed diffuse bilateral consolidations with air bronchograms (Fig. 1). 


\begin{tabular}{|l|l|}
\hline Erythrocytes & Some/ $/ \mathrm{l}$ \\
\hline Leukocytes & $10-50 / \mu \mathrm{l}$ \\
\hline Protein & $0.2-0.5 \mathrm{~g} / \mathrm{l}$ \\
\hline $\mathrm{pH}$ & 5.0 \\
\hline Ketones & $0.5-5 \mathrm{mmol} / \mathrm{l}$ \\
\hline Glucose & Negative \\
\hline
\end{tabular}

The patient was admitted to the pulmonary disease department for further evaluation. Our differential diagnosis at the time was pneumonia, diffuse alveolar bleeding or acute interstitial pneumonitis, and so antibiotics were started. A few hours after admission, the patient's clinical condition rapidly deteriorated due to progressive respiratory insufficiency and he was transferred to the Intensive Care Unit for intubation and mechanical ventilation. Echocardiography revealed no abnormalities. A computed tomography (CT) scan of the chest showed bilateral diffuse ground glass opacities without any evidence of pulmonary embolisms (Fig. 2). A diagnostic bronchoscopy had to be aborted prematurely because of hypoxia but showed a severe bilateral pulmonary haemorrhage. The results of ANA, ANCA and anti-GBM antibody tests were negative. Cultures of sputum, blood and urine remained negative. Toxicological screening of the serum revealed no signs of cocaine use. Mechanical ventilation was difficult with severe ventilatory conditions in order to achieve adequate ventilation. Eventually ventilation in the prone position was needed with $\mathrm{FiO}_{2}$ at $100 \%$ and 18 PEEP. A pulmonary biopsy would have been an appropriate next step to make a diagnosis, but we deemed the risks of complications unacceptable and therefore decided not to carry out the procedure. The initial autoimmune tests were performed using an enzyme-linked-immunosorbent assay (ELISA) assay. We therefore decided to test again for antibodies with an ELISA assay and an additional immunoblot test, which were both positive for anti-GBM antibodies. The diagnosis of anti-GBM antibody disease could therefore be established, although repeated negative testing had resulted in a diagnostic delay of 12 days. Accordingly, treatment with plasmapheresis, prednisolone and cyclophosphamide was initiated. After several weeks, a gradual clinical recovery occurred and the patient was extubated. Approximately 2 months after admission the patient was discharged in good clinical condition.

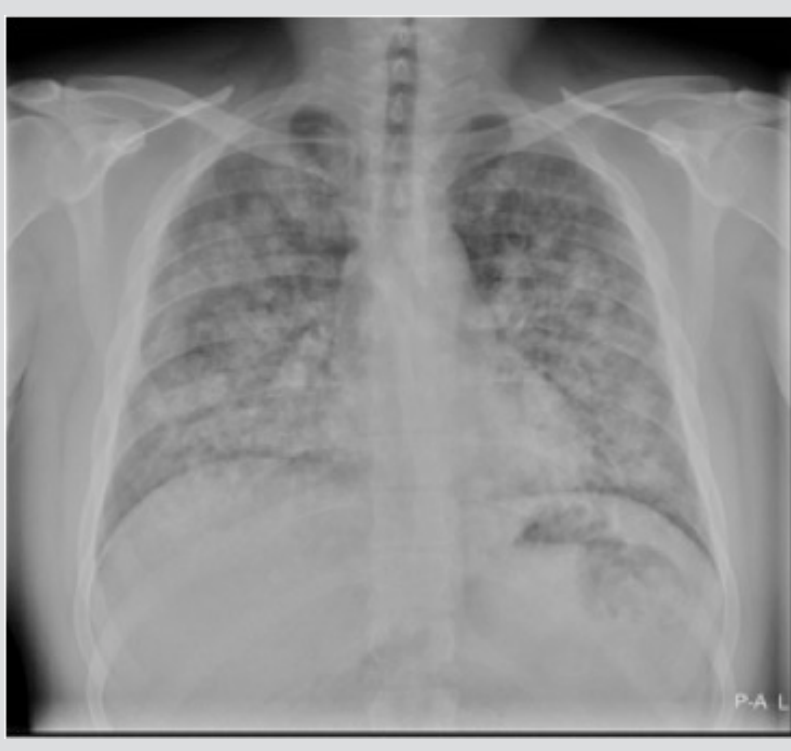

Figure 1. Postero-anterior chest radiograph obtained on the day of admission showing bilateral consolidations and air bronchogram

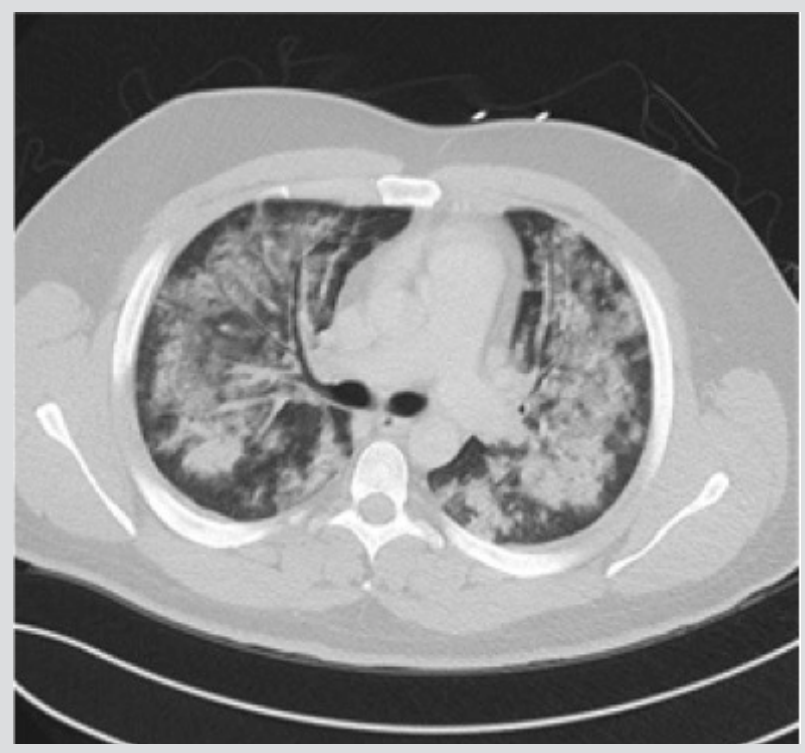

Figure 2. Chest CT scan showing extensive bilateral ground glass opacities 


\section{DISCUSSION}

Anti-GBM antibody disease is a rare organ-specific autoimmune disease, with involvement of the kidneys and lungs. The estimated incidence varies between 0.5 and 1.0 cases per million per year ${ }^{[4]}$. The incidence spikes around 20 and $60-70$ years of age ${ }^{[5]}$. No ethnic predisposition has been identified ${ }^{[6]}$. Autoantibodies primarily bind to the target alpha-3 chain of type IV collagen and activate a complement cascade that results in rapidly progressive renal and/or pulmonary damage.

The classic clinical presentation of anti-GBM antibody disease consists of renal and pulmonary symptoms. Renal manifestations include acute kidney failure with hypertension, glomerular haematuria and non-nephrotic proteinuria. Pulmonary involvement causes symptoms and signs such as coughing, shortness of breath, haemoptysis, chest pain and hypoxia. The severity of these symptoms varies widely and pulmonary haemorrhage can result in death within hours after onset despite optimal intensive care ${ }^{[7]}$.

Anti-GBM antibody disease almost always involves rapidly progressively glomerulonephritis. Additional pulmonary involvement, generally consisting of DAH, affects about $40-60 \%$ of patients ${ }^{[2]}$. Our patient, however, presented with life-threatening respiratory insufficiency due to isolated pulmonary haemorrhage. Anti-GBM antibody disease limited to the lungs is described in less than $10 \%$ of patients ${ }^{\left[{ }^{[8]}\right.}$. Overt pulmonary haemorrhage occurs almost exclusively in current smokers, like our patient, and sometimes in patients who are exposed to other bronchopulmonary irritants ${ }^{[7]}$. It is known to be precipitated by intercurrent infections and fluid overload ${ }^{[7]}$. It is unclear whether an infection was a precipitating factor in this case.

The diagnosis of anti-GBM antibody disease is based upon detection of anti-GBM antibodies in serum or a kidney or lung tissue biopsy specimen. ELISAs have a low detection threshold for anti-GBM antibodies, are highly sensitive (>95\%) and specific (>97\%) [8] and produce less than $5 \%$ false-negative results ${ }^{[8]}$. However, initial blood samples tested with ELISA on a Phadia 250 analyser were repeatedly negative in our case. After alternative diagnoses were excluded, the ELISA was repeated a third time together with an immunoblot test due to a persistently high clinical suspicion of anti-GBM antibody disease. This time these tests were positive for anti-GBM antibodies.

It is unclear what caused the initially negative ELISA results for anti-GBM antibodies. The presence of ELISA-disturbing substances is highly unlikely ${ }^{[5]}$. However, the initially negative tests could have been caused by a titre below the ELISA detection limit, since circulating serum anti-GBM antibodies are absent significantly more often in patients with anti-GBM antibody disease with intact kidney function ${ }^{[9]}$. Based on the clinical presentation of our patient, a high concentration of anti-GBM antibodies is, however, very likely. Alternatively, the negative ELISA test could have been caused by the so-called high-dose hook effect resulting in a false-negative test, but this seems unlikely and has not been previously described. In our opinion, the false-negative anti-GBM antibody results are most likely explained by entrapment of highaffinity autoantibodies in lung tissue annulling all anti-GBM antibodies, thus resulting in a circulating anti-GBM antibody level below the ELISA detection limit. This phenomenon has been described before in anti-GBM antibody disease ${ }^{[10,11]}$. In such cases, the diagnosis can be confirmed by a kidney or lung biopsy which should therefore be performed if possible in any case with a negative anti-GBM antibody result and a persistently high clinical suspicion of anti-GBM antibody disease.

Treatment of anti-GBM antibody disease consists of a combination of plasmapheresis, cyclophosphamide and high-dose prednisone. Plasmapheresis removes the pathogenic anti-GBM antibodies from the circulation, while cyclophosphamide and prednisone simultaneously prevent further autoantibody production and attenuate existing alveolar and glomerular inflammation and injury. Anti-GBM antibodies should be regularly monitored. There are no controlled trials recommending a specific length of treatment. However, plasmapheresis may be stopped when circulating anti-GBM antibodies are no longer detectable, usually after $10-14$ treatments ${ }^{[12]}$. It is very rare for anti-GBM production to resume after it has stopped. Cyclophosphamide has generally been continued for 2-3 months and prednisone for at least 3-6 months.

The prognosis of untreated anti-GBM antibody disease is extremely poor with $90 \%$ of cases resulting in death or long-term dialysis ${ }^{[2]}$. Mortality has declined since the introduction of plasmapheresis and intense immunosuppression, but kidney survival remains poor, especially when diagnosis and treatment initiation is delayed. Currently, 1-year survival is $70-90 \%$ and less than $30 \%$ of patients require long-term dialysis ${ }^{[2]}$.

In conclusion, although rare, anti-GBM antibody disease should be considered in the differential diagnosis in patients with life-threatening pulmonary haemorrhage due to isolated DAH. As demonstrated in our case, ELISA testing for anti-GBM antibodies can give false-negative results. A negative serum anti-GBM antibody test is therefore insufficient to exclude the diagnosis. Thus, a kidney or lung biopsy should be considered in any case with a high clinical suspicion but negative anti-GBM antibody test to confirm or rule out the diagnosis. 


\section{REFERENCES}

1. Jung C, Karpouzas G, Stringer WW. Dyspnea, hemoptysis, and perihilar infiltrates in a 35-year-old man. Chest 2005;127:1437-1441

2. Greco A, Rizzo MI, De Vergilio A, et al. Goodpasture's syndrome: a clinical update. Autoimmun Rev 2015;14:246-253

3. Serisier DJ, Wong RCW, Armstrong JG. Alveolar haemorrhage in anti-glomerular basement membrane disease without detectable antibodies by conventional assays. Thorax 2006;61:636-639.

4. Silvarino R, Noboa O, Cervera R. Anti-glomerular basement membrane antibodies. Isr Med Assoc J 2014;16:727-732.

5. Ohlsson S, Herlitz H, Lundberg S, et al. Circulating anti-glomerular basement membrane antibodies with predominance of subclass IgG4 and false negative immunoassay test results in anti-glomerular basement membrane disease. Am J Kidney Dis 2014:63:289-293.

6. Taylor DM, Yehia M, Simpson IJ, et al. Anti-glomerular basement membrane disease in Auckland. Intern Med J 2012;42:672-676.

7. Benz K, Amann K, Dittrich K, Hugo C, Schnur K, Dötsch J. Patient with antibody-negative relapse of Goodpasture syndrome. Clin Nephrol 2007;67:240-244.

8. Shiferaw B, Miro V, Smith C, Akella J, Chua W, Kim Z. Goodpasture's disease: an uncommon disease with an atypical clinical course. J Clin Med Res 2016;8:52-55.

9. Ang C, Savige J, Dawborn J, et al. Anti-glomerular basement membrane (GBM)-antibody-mediated disease with normal renal function. Nephrol Dial Transplant 1998;13:935939.

10. Salama AD, Dougan T, Levy JB, et al. Goodpasture's disease in the absence of circulating anti-glomerular basement membrane antibodies as detected by standard techniques. Am J Kidney Dis 2002;39:1162-1167.

11. Rutgers A, Meyers KE, Canziani G, et al. High affinity of anti-GBM antibodies from Goodpasture and transplanted Alport patients to alpha3(IV)NC1 collagen. Kidney Int 2000;58:115-122.

12. Dammacco F, Battaglia S, Gesualdo L, et al. Goodpasture' s disease: a report of ten cases and a review of the literature. Autoimmun Rev 2013;12:1101-1108. 